\title{
La voz del traductor en las novelas cultas o eruditas: El campesino de París (1979) frente a El aldeano de París (2016) de Louis Aragon
}

\author{
Marian Panchón Hidalgo \\ mpanchon@ugr.es \\ Universidad de Granada \\ Recibido: 03/06/2019 | Revisado: 16/03/2020 | Aceptado: 12/07/2020
}

\section{Resumen}

El objetivo del presente trabajo es comparar las notas de traducción de El campesino de París (1979) con las de El aldeano de París (2016) del escritor surrealista francés Louis Aragon, publicadas por Bruguera y Errata Naturae. Con ello, pretendemos confirmar el cambio que se ha experimentado en España a la hora de visibilizar al traductor en las novelas dirigidas a un público culto o erudito. Para llevar a cabo dicho análisis, nos hemos basado en la división realizada por Donaire Fernández (1991) entre notas lingüísticas y culturales. Gracias a él, hemos comprobado que ambas editoriales otorgan un papel importante a las traductoras, aunque es Errata Naturae, la de El aldeano de París (2016), la que más ha dejado oír la voz de la trujamana. Esto corrobora la evolución de la industria editorial actual, que, a través de las notas, visibiliza cada vez más la labor del traductor en las novelas de este tipo.

Palabras clave: traducción, notas del traductor, Louis Aragon, novelas eruditas

\begin{abstract}
The Translator's Voice in Educated or Scholarly Novels: Louis Aragon's El campesino de París (1979) versus El aldeano de París (2016)

The aim of this paper is to compare the translator's footnotes of French surrealist author Louis Aragon's novel El campesino de París (1979) with those of El aldeano de París (2016) in order to confirm that there has been a change, making the translator more visible in the novels intended for educated or scholarly audiences. We have based our approach on the division made by Donaire Fernández (1991) between linguistic and cultural notes. Thanks to this analysis, we have found that both publishing houses (Bruguera and Errata Naturae) give an important role to the translator, but it is Errata Naturae, publisher of El aldeano de Paris (2016), which has let the voice of the translator be more strongly heard. This corroborates the evolution of the current publishing industry, which, through these notes, makes the work of the translator in this kind of novels increasingly visible.
\end{abstract}




\section{Introducción}

La obra del escritor surrealista y comunista francés Louis Aragon (1897-1982) no comenzó a traducirse en España hasta bien entrados los años sesenta debido al estricto control censor por parte del Ministerio de Información y Turismo de la época franquista. En el caso de Le Paysan de Paris (1926), obra surrealista por excelencia, esta se tradujo por primera vez en 1979, pocos años después de la muerte del dictador Franco. La editorial barcelonesa Bruguera, interesada en literatura popular y de historietas, la publicó en España bajo el título El campesino de París y sus traductoras fueron Noëlle Boer y Victoria Cirlot. En la cubierta trasera de dicha edición se resume el contenido de la novela, donde se explica que "Louis Aragon recobra para sus ojos de poeta la mirada del campesino: una mirada original, capaz de asombro y de maravilla" y se aclara que se trata de "una lectura obligatoria" al discurrir en ella "el pensamiento de uno de los mayores poetas europeos de nuestro siglo".

Treinta y siete años después, en 2016, la madrileña Errata Naturae tradujo la misma novela de Aragon, pero con un título diferente: El aldeano de París. En las últimas páginas del libro dedicadas a las notas, la traductora Vanesa García Cazorla expone que se ha preferido traducir paysan por "aldeano", porque

aun cuando el significado más obvio de la palabra paysan sea el de "campesino", la palabra francesa posee una connotación peyorativa de la que carece la española "campesino". Por eso hemos preferido sacrificar la literalidad empleando la palabra "aldeano", que sí que posee ese matiz peyorativo, del cual se sirve Aragon de manera irónica. Cabe destacar que, salvo en el título de la obra y en el del último capítulo, la palabra paysan está del todo ausente en el texto.

Gracias a esta primera nota, observamos que García Cazorla se sitúa desde el principio en primer plano a la hora de justificar sus decisiones ("hemos preferido"). Es un claro ejemplo de la voz que se le da a lo largo de toda la obra y que iremos analizando en el presente artículo.

Al igual que en la versión de 1979, Errata Naturae opta por describir su contenido en la cubierta trasera, si bien de manera más precisa: explica que merece la pena leerla porque es "un libro fundamental de la literatura francesa, un retrato indispensable del París de la primera mitad del siglo XX, de algunos de sus personajes y, sobre todo, de sus lugares ya míticos".

Asimismo, la editorial añade en una de las solapas interiores una extensa biografía de Aragon, un gran desconocido para la mayoría de lectores españoles. En ella, Errata Naturae detalla los comienzos del escritor antes y después de conocer a André Breton y Philippe Soupault, con los que fundaría el movimiento surrealista. También se elabora un breve listado de las publicaciones escritas por él, entre las que destacan algunas de sus traducciones al español, como La Semana Santa (1953) 1 o Blanche o el olvido (1967). 
En el presente estudio, pretendemos confirmar la evolución que ha experimentado la presencia del traductor en la literatura reescrita en estos últimos años. Para ello, nos centraremos en la literatura surrealista, considerada tanto erudita, por contener prólogo y notas, como "de minorías", al ir dirigida a una pequeña parte de la sociedad por tratarse de publicaciones muy cultas y, por tanto, de difícil acceso para los que forman parte del medio popular. Definiremos las novelas cultas o eruditas como aquellas dirigidas a una parte de la sociedad con estudios superiores interesada en leer textos clásicos, generalmente anotados, prologados o epilogados.

En este tipo de literatura, el traductor suele visibilizarse, al contrario de lo que a menudo sucede en otros libros en los que se aboga por la traducción fluida, en cuyo caso se produce el efecto ilusorio de un texto "natural", es decir, un texto que no ha sido realmente traducido. Venuti (2008) explica en su teoría de la invisibilidad que la traducción fluida esconde precisamente el trabajo del traductor, así como las diferencias culturales entre países distintos. En tal situación, las estrategias para realizar una traducción fluida producen un tipo de aculturación que "naturaliza" el texto extranjero, pareciendo así "normal" para los lectores. Asimismo, esta invisibilidad expuesta por Venuti se produce por la idea individualista de autoría que continúa prevaleciendo hoy en día.

En nuestro análisis, hemos utilizado como ejemplo Le Paysan de Paris (1926), obra mayor del surrealismo francés, que relata los paseos urbanos del joven Aragon por el París de los años veinte. El escritor, en busca del "merveilleux quotidien", adopta una mirada naíf de un aldeano que descubre los lugares emblemáticos de la capital francesa. El libro se tradujo, además, dos veces: una, en 1979 y otra, en 2016.

Según Tahir-Gürçalar (2001), la retraducción puede referirse al hecho de traducir, para una lengua meta, un texto de una lengua origen que ya se ha traducido para esa misma lengua meta, o también un texto que ya posee una traducción para una lengua meta y se retraduce para esa misma lengua meta. En el caso de Le Paysan de Paris, es posible que Errata Naturae decidiera retraducir la novela de Aragon por estar descatalogada la de 1979 en España. Otra de las posibles razones son que "les traductions vieillissent" y que "aucune est la traduction : par où l'on voit que traduire est une activité soumise au temps, et une activité qui possède une temporalité propre: celle de la caducité et de l'inachèvement" (Berman, 1990: 1). En una entrevista realizada a la traductora García Cazorla ${ }^{2}$, esta nos explicó que la editorial era consciente de que ya existía una traducción del libro, pero le indicó expresamente que quería una nueva traducción.

Por otro lado, autores de la talla de Berman (ibid.) o Gambier (1994) han tratado el tema de las características de las retraducciones. La hipótesis de la retraducción defiende que las primeras traducciones suelen ser asimiladoras, o sea, se acercan al público meta. Por el contrario, las traducciones más recientes se aproximan más al texto origen. Ambos investigadores consideran, pues, que las traducciones más antiguas dan prioridad al público meta, domesticando así el texto para que la lectura sea más fluida. Sin embargo, las traducciones más recientes, al haber más posibilidades de 
acceder a la cultura del texto origen, se acercarían más a aquella cultura, optando por la extranjerización (Malta y Rael, 2015). No obstante, en Le Paysan de Paris, sucede casi lo contrario, puesto que los lectores de finales de los setenta estaban más familiarizados con la lengua y la cultura francesas que los actuales ${ }^{3}$. Efectivamente, según García Cazorla, el hecho de añadir notas le sirvió para contextualizar un libro que ya no era de actualidad para los lectores de 2016, posiblemente menos conocedores del mundo francés que los de 1979.

Por otra parte, el traductólogo Anthony Pym (1998) distingue entre retraducciones activas y pasivas. En el caso de las traducciones de Le Paysan de Paris, ambas son retraducciones pasivas, dado que las dos están alejadas tanto en el tiempo como en el espacio, y que la segunda es una verdadera reinterpretación de la obra original. En efecto, según nos confirmó García Cazorla, ella nunca llegó a leer la traducción de Bruguera antes de realizar la suya.

\section{Método de trabajo: la voz de las traductoras a través de sus notas}

El peritexto que hemos privilegiado en este artículo han sido las notas de traducción, al tratarse de lugares en los que el traductor -o el editor- deja oír su voz de manera explícita y abierta (Toledano Buendía, 2010: 639). A la hora de analizarlas, Toledano Buendía hace una división entre notas interlingüísticas y notas intralingüísticas. Las primeras tienen como objetivo acercar el TO al lector meta con el fin de ayudarle a comprender mejor el texto, y "aportando además información sobre los parámetros de producción y recepción originales" (ibid.: 5), y las segundas son una especie de reformulación; son aquellas que el traductor utiliza para dar información a partir del TM, como si de un original se tratara y sin hacer referencia al TO. En el caso de las notas de las versiones al español de Le Paysan de Paris (1926), la mayoría de ellas son de tipo interlingüístico, puesto que evidencian la presencia de las traductoras e inclinan o acercan al lector hacia la cultura original.

Según María Luisa Donaire Fernández (1991: 79), las notas de traducción “ofrecen un ámbito privilegiado para la observación en tanto que evidencian las dificultades que representa la actividad de un traductor concreto ante un texto concreto", por lo que hemos tenido en cuenta la distribución llevada a cabo por dicha investigadora entre notas culturales y lingüísticas. Las culturales son observaciones que realiza el traductor para explicar referencias de tipo cultural que aparecen en el texto traducido y que el lector quizá no comprenda por tratarse de conceptos específicos de la cultura original. Las lingüísticas, por su parte, son anotaciones difíciles de traducir a la lengua meta que sirven para aclarar al lector algunas dificultades -juegos de palabras, expresiones hechas, etc.- encontradas en el libro original. En palabras de Donaire Fernández, dichas notas de traducción pueden ordenarse jerárquicamente, según se alejen más o menos de un simple trasvase textual, en intervenciones eruditas, connotaciones culturales o lingüísticas de tipo semántico que el lector del TM no puede 
interpretar correctamente y en connotaciones culturales o lingüísticas que se pierden en la traducción.

Tanto en El campesino de París (1979) como en El aldeano de París (2016), las tres traductoras -o sus editoriales- no dudaron en incorporar notas de traducción a la obra, a pesar de que ya el original contenía anotaciones del autor.

En El campesino de París (1979), encontramos 52 notas a lo largo de todo el libro: 8 notas del autor y 44 notas de las traductoras. Las segundas se distinguen de las primeras porque la editorial incluyó las siglas "N. del T." o las palabras "Nota del Traductor" al final de la observación. Sin embargo, en algunas ocasiones, a Bruguera se le olvidó agregar esta información (p. 76 o p. 92).

Por el contrario, las 56 notas de la traductora de El aldeano de París (2016) se encuentran al final de la novela, de la página 247 a la página 259 , como indica la editorial en su nota bene ${ }^{4}$, donde agradece expresamente a García Cazorla el trabajo desempeñado: "El lector encontrará unas completísimas y sugerentes notas de la traductora -a la que los editores queremos agradecer públicamente su esfuerzo- al final de estas páginas". La decisión por parte de Errata Naturae de añadir todas las notas al final de la obra permite al público leerlas en cualquier momento y facilita así la lectura continuada del texto. No obstante, las ocho notas originales de Aragon se mantienen en la misma posición que en la versión original. De hecho, en la primera nota (p. 54), Errata Naturae indica que se trata efectivamente de notas del autor: "todas las notas al pie de esta edición son del autor".

Asimismo, en la nota bene se detalla que, a diferencia de la versión de 1979, "se han traducido la mayoría de los carteles y letreros recogidos en la edición original, tratando de reproducir fielmente el formato en el que aparecían en ella", a no ser que sean "letreros que se formulaban ya en la edición francesa en una lengua distinta a la original o que reproducían cartas de bebidas, donde los nombres eran marcas o nombres comunes a ambas lenguas". Según García Cazorla, la determinación de traducir los carteles de la obra fue suya y no de la editorial, ya que esta última no le dio ninguna directriz en ese sentido. En cambio, como observaremos a continuación, el libro de 1979 mantiene todos los letreros en francés e introduce las traducciones en forma de nota.

En el análisis que presentamos en este artículo, nos hemos centrado ante todo en las notas en las que las traductoras han dado su punto de vista o en las que se escucha claramente su voz. Con ello, lo que pretendemos es confirmar nuestra hipótesis, según la cual las editoriales que publican traducciones eruditas en la actualidad tienden a visibilizar más a los traductores que las editoriales de los años sesenta y setenta. Es importante destacar que Errata Naturae no proporcionó ninguna directriz a la traductora sobre la inclusión o no de notas, aunque la última decisión fue, evidentemente, de la editorial. 


\section{Resultados}

En lo que respecta a El campesino de París (1979), la mayoría de las notas de traducción son de tipo lingüístico: de las 44, 36 son lingüísticas y 6 son culturales ${ }^{5}$. Además, 28 notas lingüísticas son en gran parte traducciones de los carteles que las traductoras o la editorial no trasvasaron directamente en la obra, a excepción de un poema, que se optó por traducir en el libro y después se añadió una nota con el poema en francés. En la tabla 1, mostramos algunas de estas notas lingüísticas:

Tabla 1. Ejemplos de notas lingüísticas de El campesino de París (1979)

\begin{tabular}{|c|c|c|}
\hline Página & Palabra/s anotada/s & Nota de las traductoras \\
\hline 70 & $\begin{array}{c}\text { THÉÂTRE MODERNE / PRIX DES PLACES } \\
\text { / Loges et Avant-Scène / Fauteuils Avancés / } \\
\text { Réservés /1re série /Stalles /Tous droits et taxes } \\
\text { compris. }\end{array}$ & $\begin{array}{c}\text { Teatro Moderno / Precio de los asientos / Palcos y } \\
\text { Proscenio / Asientos: Delanteros, Reservados, } 1^{\text {a }} \\
\text { Clase... / Sillas. / Todos los derechos y tasas incluidos. } \\
\text { (N. del T.) }\end{array}$ \\
\hline 161 & $\begin{array}{l}\text { Ala semejante en todo al amor } \\
\text { ala por encima de ciudadelas } \\
\text { ala que sopla las candelas } \\
\text { ala batiendo olas de mares } \\
\text { ala tormenta alcanza al lindero } \\
\text { ala vuelo del alba dorada } \\
\text { ala oh los pífanos en la noche } \\
\text { ala antes de la nieve blasfema } \\
\text { ala que no es más que ella misma. }\end{array}$ & $\begin{array}{c}\text { Aile en tout pareille à l'amour, / Aile au-dessus des } \\
\text { citadelles, / Aile qui souffle les chandelles. / Aile battant } \\
\text { les flots des mers, / Aile orage atteint à l'orée, / Aile } \\
\text { envol de l'aube adorée. / Aile ô les fifres dans la nuit, } \\
\text { / Aile avant la neige blasphème, / Aile qui n'est rien } \\
\text { qu'elle-même. (N. del T.) }\end{array}$ \\
\hline 167 & $\begin{array}{c}\text { QUARTIER DU COMBAT / PLAN DU 19e } \\
\text { ARRONDISSEMENT / POINT GÉOGRAPHIQUE } \\
\text { / 48 5 52' 40" LATITUDE NORD / 0²' } 45^{\circ} " \\
\text { LONGITUDE EST ALTITUDE / AU-DESSUS DE } \\
\text { LA SEINE / AU-DESSUS DE LA MER }\end{array}$ & $\begin{array}{c}\text { Barrio du Combat / Plano del distrito } 19 \text { / Punto } \\
\text { geográfico... / latitud norte... / latitud este, altura... / } \\
\text { por encima del Sena... / por encima del mar. (N. del T.) }\end{array}$ \\
\hline 172 & $\begin{array}{l}\text { DÉPUTÉ DU 19e ARRt / MAIRE / ADJOINTS / } \\
\text { SECRÉTAIRE / CONSEILLERS MUNICIPAUX }\end{array}$ & $\begin{array}{l}\text { Diputado del Distrito } 19 . . . \text { / Alcalde... / Adjuntos... / } \\
\text { Secretario... / Consejeros Municipales. (N. del T.) }\end{array}$ \\
\hline
\end{tabular}

Todos los ejemplos de la tabla 1 son en realidad traducciones de los carteles (en francés) que Aragon descubre mientras pasea por París. También se decidió añadir una nota en la que se incluye el poema original de Aragon para que el lector pudiera comparar el original con su traducción.

Entre las notas de tipo lingüístico, hay dos relativas a connotaciones de tipo semántico que el lector meta no puede entender correctamente y tres notas que explican connotaciones que se pierden en la traducción. En la tabla 2, presentamos algunos ejemplos de esas notas de tipo lingüístico: 
Tabla 2. Ejemplos de notas lingüísticas de tipo semántico de El campesino de París (1979)

\begin{tabular}{|c|c|c|}
\hline Original (página) ${ }^{6}$ & Traducción (página) & $\begin{array}{c}\text { PALABRA ANOTADA } \\
\text { Nota de las traductoras }\end{array}$ \\
\hline $\begin{array}{l}\text { Voici que j'atteins le seuil de Certa, } \\
\text { café célèbre duquel je n'ai pas fini } \\
\text { de parler. Une devise m'y accueille } \\
\text { sur la porte au-dessus d'un pavois } \\
\text { qui groupe des drapeaux : «AMON } \\
\text { NOUS AUTES» (p. 92) }\end{array}$ & $\begin{array}{l}\text { Y llego ya a la puerta de Certa, célebre } \\
\text { café del que no he acabado aún de } \\
\text { hablar. Una divisa me acoge sobre la } \\
\text { puerta por encima de un escudo que } \\
\text { agrupa las banderas: } \\
\text { «Amon nos autes» (p. 76) }\end{array}$ & $\begin{array}{l}\text { Amon nos autes } \\
\text { Posible referencia a un juego de } \\
\text { palabras surrealista consistente } \\
\text { en la supresión de letras. Podría } \\
\text { leerse: Aimons-nous nous autres } \\
\text { (Amémonos nosotros). También } \\
\text { puede ser: Aimons nos hôtes } \\
\text { (Amemos a nuestros huéspedes). }\end{array}$ \\
\hline $\begin{array}{c}\text { ÉPHÉMÈRE } \\
\text { F.M.R. } \\
\text { (folie-mort-rêverie) } \\
\text { Les faits m'errent } \\
\text { LES FAIX, MÈRES Fernande aime } \\
\text { Robert } \\
\text { pour la vie ! ÉPHÉMÈRE } \\
\text { ÉPHÉMĖRES } \\
\text { (p. 111) }\end{array}$ & $\begin{array}{l}\text { ÉPHÉMĖRE / F.M.R. (folie-mort- } \\
\text { rêverie) / Les faits m'errent / Les faix, } \\
\text { mères / Fernande aime Robert pour la } \\
\text { vie ! / ÉPHÉMĖRE / ÉPHÉMĖRES } \\
\text { (p. 92) }\end{array}$ & $\begin{array}{l}\text { ÉPHÉMĖRE / F.M.R. (folie-mort- } \\
\text { rêverie) / Les faits m'errent / Les faix, } \\
\text { mères / Fernande aime Robert pour } \\
\text { la vie ! / ÉPHÉMĖRE / ÉPHÉMĖRES } \\
\text { Composición fonético-visual } \\
\text { intraducible a partir del término } \\
\text { efímero / F. M. R. / locura-muerte- } \\
\text { ensueño / Los hechos me dan } \\
\text { vueltas / Las cargas, madres / } \\
\text { Fernando quiere a Roberto / por la } \\
\text { vida / Efímero / Efímeros. (N. del T.) }\end{array}$ \\
\hline $\begin{array}{l}\text { Il y a des mots qui sont des miroirs, } \\
\text { des lacs optiques vers lesquels les } \\
\text { mains se tendent en vain. Syllabes } \\
\text { prophétiques : mon cher Desnos, } \\
\text { prenez garde aux femmes dont le } \\
\text { nom sera Faënzette ou Françoise, } \\
\text { prenez garde à ces feux de paille } \\
\text { qui pourraient devenir des bûchers, } \\
\text { ces femmes éphémèrement aimées, } \\
\text { ces Florences, ces Ferminas, qu'un } \\
\text { rien enflamme ET FAIT MĖRES. (p. } \\
\text { 111-112) }\end{array}$ & $\begin{array}{l}\text { Hay palabras que son espejos, lagos } \\
\text { ópticos hacia los que las manos se } \\
\text { extienden en vano. Sílabas proféticas: } \\
\text { mi querido Desnos, tenga cuidado } \\
\text { con las mujeres cuyo nombre sea } \\
\text { Faënzette o Françoise, tenga cuidado } \\
\text { con estos fuegos de paja que podrían } \\
\text { convertirse en hogueras, estas } \\
\text { mujeres efímeramente amadas, estas } \\
\text { Florences, estas Ferminas que una } \\
\text { nada inflama y LAS HACE MADRES. } \\
\text { (p. 92) }\end{array}$ & $\begin{array}{c}\text { Et fait mères } \\
\text { Mismo juego fonético-visual (F. M. } \\
\text { R.) }\end{array}$ \\
\hline $\begin{array}{c}\text { [...] puis par-dessus des sentinelles } \\
\text { gelées les messages des rossignols } \\
\text { se croisent avec la course ventre } \\
\text { à terre des rats blancs, tandis que } \\
\text { sur un appui de croisée une lettre } \\
\text { d'affaires, qui n'est pas précisément } \\
\text { une lettre d'affaires, mais un prétexte, } \\
\text { allons tranchons le mot une lettre } \\
\text { d'amour, s'envole, vole, vole. Ah j'ai } \\
\text { vu sur le toit la douche marche des } \\
\text { voleurs. (p. 211) }\end{array}$ & $\begin{array}{c}\text { [...] luego por encima de los centinelas } \\
\text { helados los mensajes de los ruiseñores } \\
\text { se cruzan con el trayecto a galope } \\
\text { tendido de ratas blancas, mientras } \\
\text { que en el antepecho de una ventana } \\
\text { una carta de negocios que no es } \\
\text { precisamente una carta de negocios, } \\
\text { sino un pretexto, precisemos entonces } \\
\text { la palabra, una carta de amor echa a } \\
\text { volar, vuela, vuela. Ah, he visto sobre el } \\
\text { tejado la suave marcha de los ladrones. } \\
\text { (p. 178) }\end{array}$ & $\begin{array}{c}\text { Ladrones } \\
\text { El término ladrón, en francés voleur, } \\
\text { se lo sugiere posiblemente a Aragon } \\
\text { la frase anterior con un juego de } \\
\text { palabras intraducible al castellano: } \\
\text { s'envole, vole, vole. /.../ des voleurs. } \\
\text { (N. del T.) }\end{array}$ \\
\hline
\end{tabular}

En los ejemplos que hemos seleccionado, oímos efectivamente la voz de las traductoras, puesto que ambas dan su opinión respecto al significado de los términos. No obstante, utilizan la forma impersonal cuando dan su punto de vista ("podría leerse", "también puede ser" o "se lo sugiere posiblemente a Aragon"), por lo que se apartan de lo que escriben, dando así menos importancia a su figura y a su autoridad. 
En el primer caso, las traductoras explican que la frase Amon nos autes (p. 76), es una "posible referencia" a un juego de palabras surrealista. Lo mismo sucede en páginas sucesivas, en las que consideran que la composición fonético-visual ÉPHÉMÈRE (p. 92) es "intraducible", así como otro juego de palabras "intraducible" que surge "posiblemente" a partir del término ladrones (p. 178).

En cuanto a las seis notas culturales, cuatro de ellas son eruditas, una es de tipo semántico para que el lector consiga interpretar el término, y otra es una nota que han añadido porque la connotación francesa se pierde en español (tabla 3):

Tabla 3. Ejemplos de notas culturales de El campesino de París (1979)

\begin{tabular}{|c|c|c|}
\hline Original (página) & Traducción (página) & $\begin{array}{c}\text { PALABRA ANOTADA } \\
\text { Nota de las traductoras }\end{array}$ \\
\hline $\begin{array}{l}\text { Il y avait alors un tribunal de Salut } \\
\text { Dada et rien ne faisait prévoir } \\
\text { qu'à la Terreur succéderait un jour } \\
\text { le Directoire, avec ses jeux, ses } \\
\text { incroyables et ses robes fendues. } \\
\text { (p. 73) }\end{array}$ & $\begin{array}{l}\text { Había entonces un tribunal de } \\
\text { Salvación Dada y nada hacía prever } \\
\text { que al Terror sucedería un día el } \\
\text { Directorio, con sus juegos, sus } \\
\text { incroyables y sus trajes rasgados. } \\
\text { (p. 61) }\end{array}$ & $\begin{array}{c}\text { Incroyables } \\
\text { Elegantes de la época del Directorio } \\
(\mathrm{N} \text {. del T) }\end{array}$ \\
\hline $\begin{array}{c}\text { Cela vaut bien d'avoir réussi à faire } \\
\text { apprendre aux lycéens un poème } \\
\text { où le laurier parle à la première } \\
\text { personne. (p. 128) }\end{array}$ & $\begin{array}{l}\text { Ello ha hecho que los bachilleres } \\
\text { aprendan un poema donde el laurel } \\
\text { habla en primera persona (p. 107) }\end{array}$ & $\begin{array}{l}\text { Un poema donde el laurel habla en } \\
\text { primera persona } \\
\text { Se refiere al poema de Théodore de } \\
\text { Banville. (Nota del traductor) }\end{array}$ \\
\hline $\begin{array}{l}\text { [...] on insultait à la vie en opposant à } \\
\text { la figure majestueuse de la Pierre un } \\
\text { Déroulède verdissant; [...]. (p. 189) }\end{array}$ & $\begin{array}{l}{[\ldots] \text { se insultaba a la vida oponiendo }} \\
\text { a la figura majestuosa de la piedra un } \\
\text { verdecino Déroulède. (p. 158) }\end{array}$ & $\begin{array}{c}\text { Déroulède } \\
\text { Se refiere a la estatua del general. } \\
(\mathrm{N} . \text { del T. })\end{array}$ \\
\hline $\begin{array}{l}\text { Le fond de son discours qui se } \\
\text { confond avec le fond de l'air est une } \\
\text { équivoque établie entre les arbres } \\
\text { et les mots, la prairie ressemble à } \\
\text { un limmerick, it was a young lady of } \\
\text { Gloucester, [...]. (p. 220-221) }\end{array}$ & $\begin{array}{c}\text { El fondo de su discurso que se } \\
\text { confunde con el fondo del aire es un } \\
\text { equívoco establecido entre los árboles } \\
\text { y las palabras, la pradera se parece } \\
\text { a un limmerick, it was a Young lady of } \\
\text { Gloucester, [...]. (p. 186) }\end{array}$ & $\begin{array}{l}\text { Limmerick } \\
\text { Especie de poema corto absurdo y } \\
\text { jocoso. (N. del T.) }\end{array}$ \\
\hline $\begin{array}{c}\text { J'abandonne aux rêveurs ces trous } \\
\text { du faux rocher pour y cacher leurs } \\
\text { hiboux et leurs araignées fileuses, et } \\
\text { que les journalistes, révérence parler, } \\
\text { développent ce thème à coulisse : les } \\
\text { grottes sont les moniches de l'ombre } \\
\text { et j'y jouis. (p. 221) }\end{array}$ & $\begin{array}{c}\text { Les dejo a los soñadores estos orificios } \\
\text { del falso peñasco para esconder sus } \\
\text { búhos y sus arañas hiladoras y que los } \\
\text { periodistas, con perdón, desarrollen } \\
\text { este tema hasta la última asociación. } \\
\text { (p. 186-187) }\end{array}$ & $\begin{array}{l}\text { Recuérdese que ésta era la base de } \\
\text { todo juego surrealista. (N. del T.) }\end{array}$ \\
\hline $\begin{array}{l}\text { Je marche sur leurs corps, roi fainéant } \\
\text { j'avance, je salis leurs vestons, et leur } \\
\text { peau, et leur cœur. Drôles de dessins } \\
\text { de l'Aubusson servile. (p. 222) }\end{array}$ & $\begin{array}{c}\text { Ando sobre sus cuerpos, rey holgazán, } \\
\text { yo avanzo, mancho sus americanas, } \\
\text { su piel y su corazón. Raros dibujos del } \\
\text { servil Aubusson, (p. 188) }\end{array}$ & $\begin{array}{c}\text { Aubusson } \\
\text { Importante manufactura de tapices. } \\
(\mathrm{N} \text {. del T.) }\end{array}$ \\
\hline
\end{tabular}

En la tabla 3, comprobamos que las traductoras continúan permaneciendo visibles, pero se mantienen igual de impersonales que en los ejemplos anteriores relacionados con las notas lingüísticas de tipo semántico (como "recuérdese"). En el caso de las no- 
tas culturales, Noëlle Boer y Victoria Cirlot expresan su opinión, pero de manera más escueta: da la impresión de que las dos aportan la información sin apenas reflexionar. Además, en sus anotaciones, dan a entender que los lectores son conocedores del autor y de la historia francesa, ya que explican brevemente que el poema al que se refiere Aragon (p. 107), por ejemplo, pertenece a Théodore de Banville, o que los Incroyables (p. 61) son los "elegantes de la época del Directorio", sin proporcionar ningún tipo de explicación complementaria en ambos casos.

En lo que se refiere a El aldeano de París (2016), García Cazorla incorporó 56 notas, de las cuales 23 son lingüísticas y 33 son culturales. La gran mayoría de ellas son eruditas y de tipo enciclopédico, lo que evidencia el gran conocimiento de la traductora respecto al texto traducido, dando así más información de la proporcionada por el libro original. A continuación, se detallan varios ejemplos de notas lingüísticas eruditas (tabla 4):

Tabla 4. Ejemplos de notas lingüísticas eruditas de El aldeano de París (2016)

\begin{tabular}{|c|c|c|}
\hline Original (página) & Traducción (página) & $\begin{array}{l}\text { PALABRA ANOTADA } \\
\text { Nota de la traductora }\end{array}$ \\
\hline $\begin{array}{l}\text { Dans vos châteaux de } \\
\text { sable que vous êtes } \\
\text { belles, colonnes de } \\
\text { fumées! (p. 15) }\end{array}$ & $\begin{array}{c}\text { ¡Qué bellas estáis, columnas } \\
\text { de humo, en vuestros } \\
\text { castillos de arena! (p. 13) }\end{array}$ & $\begin{array}{l}\text { Humo } \\
\text { En el original francés, colonnes de fumées. La palabra } \\
\text { fumée significa literalmente "humo", pero en sentido } \\
\text { figurado significa también - como en castellano - algo } \\
\text { efímero, vano y perecedero. Fumées (en plural) se refiere } \\
\text { asimismo a los "vapores" en el sentido que antiguamente } \\
\text { se le daba al término de "humor sutil que se elevaba } \\
\text { desde el estómago u otra parte del cuerpo a la cabeza, } \\
\text { aturdiéndola o mortificándola"; como en la expresión "los } \\
\text { vapores del vino" para simbolizar la ebriedad. A lo largo de } \\
\text { todo el texto, Aragon emplea la palabra fumée en sus tres } \\
\text { sentidos: como humo que entorpece la vista (o que enturbia } \\
\text { el entendimiento); como algo efímero y vano; y, por último, } \\
\text { como algo embriagador, algo que arroba, que produce } \\
\text { quimeras en nuestra mente, en definitiva, la maravilla. Se } \\
\text { trata de tres ideas que, expresadas de muy diversa manera, } \\
\text { están presentes en todo el texto. }\end{array}$ \\
\hline $\begin{array}{l}\text { Elle règne bizarrement } \\
\text { dans ces sortes de } \\
\text { galeries couvertes qui } \\
\text { sont nombreuses à } \\
\text { Paris aux alentours des } \\
\text { grands boulevards et } \\
\text { que l'on nomme d'une } \\
\text { façon troublante des } \\
\text { passages, comme } \\
\text { si dans ces couloirs } \\
\text { dérobés au jour, il n'était } \\
\text { permis à personne } \\
\text { de s'arrêter plus d'un } \\
\text { instant. (p. 20-21) }\end{array}$ & $\begin{array}{l}\text { Esta luz reina extrañamente } \\
\text { en esa suerte de galerías } \\
\text { cubiertas que son numerosas } \\
\text { en París en los aledaños } \\
\text { de los grandes bulevares y } \\
\text { que, de forma inquietante, } \\
\text { llamamos "pasajes", como si } \\
\text { en esos pasadizos ocultos a } \\
\text { la luz del día, no le estuviera } \\
\text { permitido a nadie detenerse } \\
\text { más de un instante. (p. 18) }\end{array}$ & $\begin{array}{c}\text { Pasajes } \\
\text { En el original, passage. Puede que sea ésta la palabra } \\
\text { más repetida en el texto original. Sin embargo, posee } \\
\text { numerosísimos significados, por lo que, en función del } \\
\text { contexto, la hemos traducido como "paso", "transición", } \\
\text { "andadura", etc. En casi todas estas acepciones subyace } \\
\text { la idea de lo efímero, el cambio, el movimiento, la } \\
\text { metamorfosis e incluso, como veremos más adelante, la } \\
\text { idea de "tránsito" en el sentido del paso de la vida a la } \\
\text { muerte. }\end{array}$ \\
\hline
\end{tabular}




\begin{tabular}{|c|c|c|}
\hline Original (página) & Traducción (página) & $\begin{array}{l}\text { PALABRA ANOTADA } \\
\text { Nota de la traductora }\end{array}$ \\
\hline $\begin{array}{l}\text { L'autre contient encore } \\
\text { quelques cannes et } \\
\text { parapluies et aussi } \\
\text { des portefeuilles, de } \\
\text { petits sacs de perles, } \\
\text { des colliers d'ambre et, } \\
\text { suivant une disposition } \\
\text { étrange et concertée, } \\
\text { des pipes font une grave } \\
\text { cercle de muettes à la } \\
\text { partie moyenne, où la } \\
\text { lumière, en jouant, vient } \\
\text { caresser leurs têtes } \\
\text { hétéroclites. (p. 33) }\end{array}$ & $\begin{array}{l}\text { El otro contiene algunos } \\
\text { bastones, además de } \\
\text { paraguas, carteras, saquitos } \\
\text { de perlas, collares de ámbar } \\
\text { y, siguiendo una disposición } \\
\text { extraña y concertada, pipas } \\
\text { formando un grave círculo } \\
\text { de silentes corcheas en la } \\
\text { parte central, donde la luz, a } \\
\text { modo de juego, acaricia sus } \\
\text { heteróclitas cabezas. (p. } 30 \text { ) }\end{array}$ & 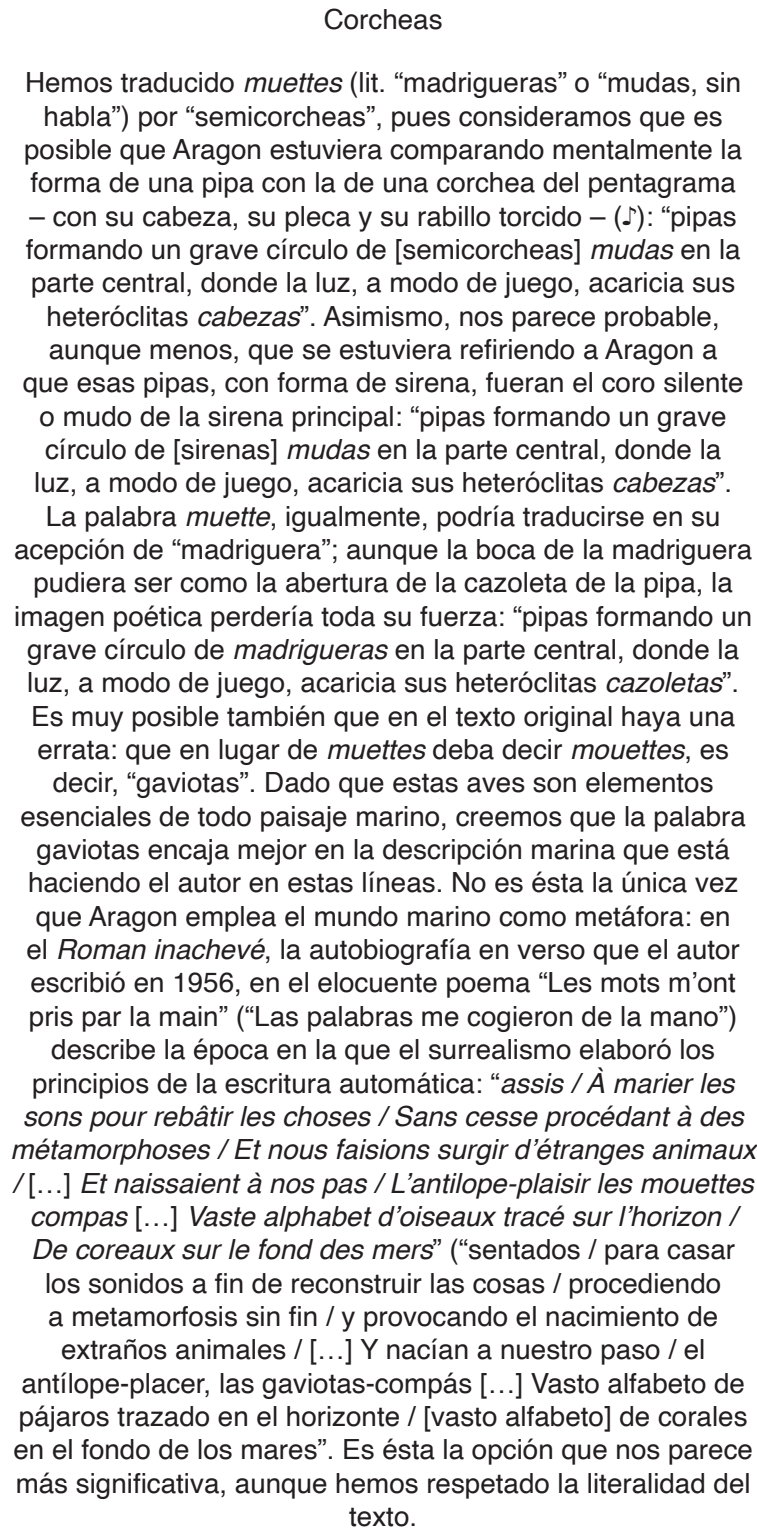 \\
\hline $\begin{array}{l}\text { Le dessein de fiction, } \\
\text { et tout l'air aimable } \\
\text { qu'il nécessite, les } \\
\text { tours d'intelligence } \\
\text { des fictionnaires de } \\
\text { l'esprit, valent-ils tout ce } \\
\text { comportement d'écriture } \\
\text { et d'imprimerie, les } \\
\text { épreuves corrigées, et } \\
\text { les petits battements } \\
\text { de votre cœur, } \\
\text { mensuellement, à la } \\
\text { mise en pages? (p. 223) }\end{array}$ & $\begin{array}{l}\text { ¿Acaso el designio de la } \\
\text { ficción y la amable atmósfera } \\
\text { que ésta requiere, así } \\
\text { como las acrobacias de la } \\
\text { inteligencia de los ficcionarios } \\
\text { del espíritu pueden merecer } \\
\text { todas esas rutinas de } \\
\text { escritura e imprenta, las } \\
\text { pruebas corregidas y } \\
\text { los latiditos de vuestros } \\
\text { corazones mensualmente } \\
\text { cada vez que realizáis la } \\
\text { compaginación? (p. 219) }\end{array}$ & $\begin{array}{l}\text { Ficcionarios } \\
\text { En el original, fictionnaire, palabra inventada por Aragon. }\end{array}$ \\
\hline
\end{tabular}


En efecto, como se refleja en la tabla 4, García Cazorla interpreta minuciosamente cada término. Por ejemplo, para "humo"/ fumée, ella misma aclara que la palabra francesa puede significar "humo", "algo efímero" o "vapores" y que, en la novela, Aragon emplea fumée en el sentido de "humo que entorpece la vista", como algo "efímero y vano" y como "algo embriagador", facilitando así la lectura de su traducción. También se intenta justificar cuando emplea un término: según ella, "pasajes" tiene "numerosísimos significados" y que "en función del contexto, la hemos traducido por 'paso', 'transición', 'andadura', etc.'. Asimismo, para muettes, García Cazorla ha determinado traducir esa palabra por "semicorcheas" y ella misma interpreta su significado detallando que "es posible que Aragon estuviera comparando mentalmente la forma de una pipa con la de una corchea del pentagrama". Del mismo modo, da su punto de vista cuando expresa que "nos parece probable [...] que se estuviera refiriendo a Aragon a que esas pipas [...] fueran el coro silente o mudo", aunque también muettes "podría traducirse en su acepción de "madriguera". No obstante, según ella, es "muy posible también que en el texto original haya una errata" y que en realidad Aragon estuviera haciendo alusión a mouettes, es decir, "gaviotas". A pesar de eso, concluye la nota explicando que "es ésta la opción que nos parece más significativa, aunque hemos respetado la literalidad del texto", por lo que finalmente empleó la palabra "corchea" (muette). He aquí, pues, un claro ejemplo de los continuos razonamientos de la traductora. En ellos, García Cazorla aclara casi siempre el porqué de sus decisiones cuando escoge un término en concreto, haciendo partícipe al lector de todas sus elecciones.

A diferencia de lo que sucede en la traducción de 1979, García Cazorla evita emplear de nuevo la forma impersonal y opta por incluirse a sí misma cuando da su opinión o cuando explica cómo ha traducido un término en concreto ("hemos traducido", "consideramos que es posible", "nos parece probable", "nos parece más significativa" o "hemos respetado"), visibilizando automáticamente su labor y mostrando al lector que, gracias a ella, puede leer dicha versión del texto. Así pues, en estos ejemplos, su presencia es más obvia que en las notas del de 1979, donde se prefiere hacer uso de la voz impersonal cuando las traductoras dan su punto de vista. En la entrevista realizada a García Cazorla, esta reconoció su responsabilidad a la hora de escribir esas notas, por lo que, inconscientemente, se incluyó en esa toma de deliberaciones. Según ella, estas anotaciones constituían una manera de comunicar con el lector y aclararle que en la traducción quizá haya cosas que no se entiendan o que su traducción oculte otras posibles lecturas del texto original. Como ella misma resumió: "es una manera de decir que la traducción la ha hecho una persona: si la hiciera otra persona, la traducción no sería la misma, sería mejor o peor, pero nunca la misma".

En la tabla 5, detallamos también otros ejemplos de notas eruditas, aunque esta vez de tipo cultural: 
Tabla 5. Ejemplos de notas culturales eruditas de El aldeano de París (2016)

\begin{tabular}{|c|c|c|}
\hline Original (página) & Traducción (página) & $\begin{array}{l}\text { PALABRA ANOTADA } \\
\text { Nota de la traductora }\end{array}$ \\
\hline $\begin{array}{l}\text { N'y a-t-il pas des coiffeurs } \\
\text { qui aient songé, comme des } \\
\text { mineurs dans la houille, à } \\
\text { ne servir jamais que des } \\
\text { brunes, ou d'autres à se } \\
\text { lancer dans le blond? (p. 50) }\end{array}$ & $\begin{array}{l}\text { ¿No hay peluqueros que, como } \\
\text { los mineros en las minas de } \\
\text { hulla, hayan soñado con servir } \\
\text { solamente a las morenas, y otros } \\
\text { que se hayan entregado a las } \\
\text { rubias? (p. 47) }\end{array}$ & $\begin{array}{l}\text { Rubias } \\
\text { Comienza aquí la letanía de los rubios. El } 1 \text { de abril } \\
\text { de 1922, la revista Littérature publica un cuestionario } \\
\text { con treinta y siete preguntas en el que participan } \\
\text { Péret, Éluard, Breton y Aragon. En lo referente a los } \\
\text { colores, Aragon elige el amarillo. }\end{array}$ \\
\hline $\begin{array}{l}\text { La chevelure morte eut tout } \\
\text { à coup un reflet de porto : } \\
\text { le coiffeur commençait les } \\
\text { ondulations de Marcel. } \\
\text { (p. 52-53) }\end{array}$ & $\begin{array}{c}\text { Aquella cabellera inerte adquirió } \\
\text { de súbito el reflejo de un oporto: } \\
\text { el peluquero comenzaba a } \\
\text { hacerle un ondulado Marcel. } \\
\text { (p. 49) }\end{array}$ & $\begin{array}{l}\text { Ondulado Marcel } \\
\text { En 1875, en plena Belle Époque, Marcel Grateau } \\
\text { inventó las tenacillas que harían posible uno de los } \\
\text { peinados que mayor furor causarían años más tarde, } \\
\text { en las décadas veinte y treinta del siglo siguiente, } \\
\text { esas ondas que, a ritmo de charlestón, ondeaban en } \\
\text { locales como Le Bœuf sur le Toit. }\end{array}$ \\
\hline $\begin{array}{c}\text { Un bonnisseur s'y tient } \\
\text { perpétuellement frappant } \\
\text { de la canne une affiche } \\
\text { du Théâtre Moderne ; des } \\
\text { bouffées de shimmy se } \\
\text { mêlent à son discours, } \\
\text { attirant les regards vers le } \\
\text { marchand de musique qu'on } \\
\text { aperçoit à gauche, tout } \\
\text { tapissé d'éditions Salabert. } \\
\text { (p. 74) }\end{array}$ & $\begin{array}{l}\text { Hay allí, perpetuamente, un } \\
\text { charlatán golpeando con su } \\
\text { bastón un cartel del Théâtre } \\
\text { Moderne: las ráfagas de } \\
\text { sonidos del shimmy se funden } \\
\text { con su palabrería, atrayendo } \\
\text { las miradas hacia la tienda } \\
\text { de música que vemos a la } \\
\text { izquierda, tapizada con las } \\
\text { ediciones musicales de la casa } \\
\text { Salabert. (p. 71). }\end{array}$ & $\begin{array}{l}\text { Casa Salabert } \\
\text { La casa Éditions Salabert fue fundada en } 1878 \\
\text { por Édouard Salabert. Al frente de ésta, le sucedió } \\
\text { su hijo, Francis, quien sería el primero en editar } \\
\text { la música del Grupo de los Seis (Francis Poulenc, } \\
\text { Georges Auric, Arthur Honneger, Darius Milhaud, } \\
\text { Lois Durey y Germaine Tailleferre), además de la de } \\
\text { su mentor, Erik Satie. En su catálogo encontramos } \\
\text { también a grandes figuras del jazz, como Duke } \\
\text { Ellington o Joséphine Baker, pero también a grandes } \\
\text { cantantes de la "música ligera", como Charles } \\
\text { Trenet, Edith Piaf, Mistinguett o Marlene Dietrich. }\end{array}$ \\
\hline $\begin{array}{l}\text { L'esthétique d'Eugène } \\
\text { Manuel lui parut aussi un } \\
\text { remède à cette genèse } \\
\text { surnaturelle. (p. 188) }\end{array}$ & $\begin{array}{l}\text { La estética de Eugène Manuel } \\
\text { le pareció asimismo el remedio } \\
\text { para esta sobrenatural génesis. } \\
\text { (p. 184) }\end{array}$ & $\begin{array}{l}\text { Eugène Manuel } \\
\text { Eugène Manuel (1823-1901) fue un poeta y político } \\
\text { francés perteneciente al movimiento parnasianista. }\end{array}$ \\
\hline
\end{tabular}

En esta ocasión, la traductora aporta nuevamente más información que el libro original para que así los lectores de lengua española puedan entender algunos conceptos culturales. No obstante, se trata de términos que ni siquiera un lector francés entendería en la actualidad. Así, el llamado peinado "ondulado Marcel", la "casa Salabert" o "Eugène Manuel" son completamente desconocidos para una gran parte del lectorado galo del siglo XXI. Es importante aclarar que las últimas ediciones de Le Paysan de Paris de la clásica editorial Gallimard -y su colección de bolsillo Folio- carecen de notas culturales ${ }^{7}$, a diferencia de lo que sucede en la traducción de Errata Naturae. En dichos casos, García Cazorla se incluye una vez más en los comentarios al utilizar la primera persona del plural ("encontramos").

En lo que respecta a las connotaciones culturales o lingüísticas de tipo semántico que el lector español quizá no pueda entender correctamente, encontramos algunos ejemplos de esta categoría (tabla 6): 
Tabla 6. Ejemplos de notas culturales y lingüísticas de tipo semántico de El aldeano de París (2016)

\begin{tabular}{|c|c|c|}
\hline Original (página) & Traducción (página) & $\begin{array}{l}\text { PALABRA ANOTADA } \\
\text { Nota de la traductora }\end{array}$ \\
\hline $\begin{array}{l}\text { Ce garni romantique, dont } \\
\text { les portes bâillent parfois, } \\
\text { laissant apercevoir de } \\
\text { bizarres coquillages, la } \\
\text { disposition des lieux le rend } \\
\text { plus équivoque encore que } \\
\text { l'emploi peut-être banal } \\
\text { qu'une population flottante } \\
\text { en peut faire. (p. 24) }\end{array}$ & $\begin{array}{c}\text { A esta romántica casa } \\
\text { de huéspedes, cuyas } \\
\text { puertas en ocasiones están } \\
\text { entreabiertas, dejando } \\
\text { columbrar en su interior } \\
\text { extravagantes almejas, la } \\
\text { disposición de los espacios } \\
\text { lo vuelve más sospechoso } \\
\text { aún que el uso, tal vez banal, } \\
\text { que hace de él su población } \\
\text { flotante. (p. 22) }\end{array}$ & $\begin{array}{l}\text { Almejas } \\
\text { Tómese "almejas" en el sentido vulgar de la palabra. } \\
\text { En el original Aragon emplea la palabra coquillage, } \\
\text { que además de significar "concha" o "marisco" se } \\
\text { refiere vulgarmente al órgano genital femenino. Dado } \\
\text { el contexto y el lenguaje licencioso que, en ocasiones, } \\
\text { el autor emplea a lo largo del texto, nos hemos } \\
\text { decantado por esta opción. }\end{array}$ \\
\hline $\begin{array}{l}\text { Le blond échappe à ce qui } \\
\text { définit, par une sorte de } \\
\text { chemin capricieux où je } \\
\text { rencontre les fleurs et les } \\
\text { coquillages. (p. } 52 \text { ) }\end{array}$ & $\begin{array}{l}\text { El rubio se escapa a toda } \\
\text { definición por una suerte de } \\
\text { senda caprichosa en la que } \\
\text { salen a mi encuentro flores y } \\
\text { almejas. (p. } 48 \text { ) }\end{array}$ & $\begin{array}{l}\text { Flores y almejas } \\
\text { Entiéndase esta frase en sentido figurado: nótese } \\
\text { que tanto la palabra castellana "flor" como su } \\
\text { correspondiente francesa, fleur, significan "virginidad" } \\
\text { y que, como ya se ha visto, coquillage, en lenguaje } \\
\text { vulgar, significa "almeja" en referencia a la vulva. }\end{array}$ \\
\hline $\begin{array}{c}\text { Ce n'est pas le cas du porto } \\
\text { de Certa : chaud, ferme, } \\
\text { assuré, et véritablement } \\
\text { timbré. (p. 96) }\end{array}$ & $\begin{array}{l}\text { No es éste el caso del } \\
\text { oporto del Certâ: cabezón, } \\
\text { consistente, con mucho } \\
\text { cuerpo y, verdaderamente, } \\
\text { timbrado. (p. 92) }\end{array}$ & $\begin{array}{l}\text { Timbrado } \\
\text { En el original, timbré (la cursiva es de Aragon). Timbré, } \\
\text { además del sentido de "timbrado" o "provisto de una } \\
\text { etiqueta con denominación de origen", tiene el sentido } \\
\text { de "loco" o "alocado". }\end{array}$ \\
\hline $\begin{array}{l}\text { C'est à cet instant que je } \\
\text { rêve et que je vois dans l'air } \\
\text { le spectre absurde de mon } \\
\text { sort. (p. 157) }\end{array}$ & $\begin{array}{l}\text { En ese cabal instante es } \\
\text { cuando sueño y veo en el } \\
\text { aire el espectro absurdo de } \\
\text { mi suerte. (p. 153) }\end{array}$ & $\begin{array}{l}\text { Suerte } \\
\text { En el original francés, de mon sort. Comienza aquí un } \\
\text { juego con la palabra sort, que tiene varios significados: } \\
\text { en este primer caso, significa "suerte" en el sentido de } \\
\text { "hado, destino". Más adelante, en su personificación } \\
\text { del tedio, Aragon dice de éste: il en sort, es decir, } \\
\text { emplea la tercera persona singular del verbo (en) } \\
\text { sortir ("abandonar un lugar"), y un poco más adelante, } \\
\text { dice j'en sors. Por otro lado, y esto es muy importante } \\
\text { también, en sortir también significa "llevar una tarea } \\
\text { a cabo, terminarla, acabarla, culminarla, llevarla a su } \\
\text { fin". A todo esto hay que añadir que el verbo sortir } \\
\text { significa etimológicamente "decidir por la suerte", es } \\
\text { decir, "echar a suertes, decidir algo confiándolo a la } \\
\text { suerte, al azar". En castellano, el verbo salir - que } \\
\text { sería la traducción más obvia de este verbo francés } \\
\text { - mantiene el sentido de la suerte en una de sus } \\
\text { acepciones, la de "ser elegido o sacado por suerte", } \\
\text { como, por ejemplo, en la lotería los números un } \\
\text { sentido que hemos querido mantener cuando unos } \\
\text { párrafos más allá el tedio "sale". Dada la importancia } \\
\text { que Aragon atribuye a la casualidad, al azar, en las } \\
\text { líneas que aparecen a continuación, hemos traducido } \\
\text { el verbo sortir en sus tres sentidos: salir, acabar algo } \\
\text { (o con algo) y el del azar. }\end{array}$ \\
\hline
\end{tabular}

Al igual que en anteriores ocasiones, la traductora interpreta el texto original y afronta explícitamente su responsabilidad. Por ejemplo, en "almejas"-coquillages en francés-, considera que este vocablo se tiene que entender en su sentido vulgar. Como 
Aragon emplea a veces un lenguaje licencioso, la traductora se ha inclinado por esa opción. En otra ocasión, calca incluso un término del francés a la hora de trasvasar un concepto: en lugar de emplear "loco" por timbré, prefiere utilizar "timbrado", aunque se ve obligada a justificar su decisión en una nota a pie de página. Por último, para el sustantivo "suerte", García Cazorla redacta una larga nota para aclarar los diferentes significados de sort, llegando incluso a detallar la etimología del término y la razón por la que tradujo el verbo sortir en sus tres acepciones. Una vez más, la trujamana explica el porqué de su traducción y se incluye en las explicaciones ("nos hemos decantado por esta opción" o "hemos traducido el verbo sortir en sus tres sentidos"). No obstante, en la nota que hace alusión a la página 48, esta utiliza también la forma impersonal ("nótese", "entiéndase").

En último lugar, cabe destacar las notas de connotaciones culturales o lingüísticas que se pierden en la traducción (tabla 7):

Tabla 7. Notas culturales y lingüísticas de términos que se pierden en la traducción en El aldeano de París (2016)

\begin{tabular}{|c|c|c|}
\hline Original (página) & Traducción (página) & $\begin{array}{l}\text { PALABRA ANOTADA } \\
\text { Nota de la traductora }\end{array}$ \\
\hline $\begin{array}{l}\text { Qu'y a-t-il de plus blond que } \\
\text { la mousse? (p. 52) }\end{array}$ & $\begin{array}{c}\text { ¿Acaso hay algo más rubio } \\
\text { que la espuma y el musgo? } \\
\text { (p. 48) }\end{array}$ & $\begin{array}{l}\text { La espuma y el musgo } \\
\text { En razón del contexto, hemos traducido por "espuma" } \\
\text { y “musgo" una única palabra: mousse, que además de } \\
\text { estas dos acepciones significa "melena". }\end{array}$ \\
\hline $\begin{array}{c}\text { ÉPHÉMÈRE } \\
\text { F.M.R. } \\
\text { (folie-mort-rêverie) } \\
\text { Les faits m'errent } \\
\text { LES FAIX, MÈRES Fernande } \\
\text { aime Robert } \\
\text { pour la vie ! ÉPHÉMĖRE } \\
\text { ÉPHÉMÈRES } \\
\text { (p. 111) }\end{array}$ & $\begin{array}{l}\text { Efímero. F. M. R. (Folía - } \\
\text { muerte - reflejo). En mí erro. } \\
\text { Es, sí, eros. Fi ama a ro. } \\
\text { ¡Para toda la vida! Efímero. } \\
\text { Efímeros. (p. 107) }\end{array}$ & $\begin{array}{l}\text { Efímero. F. M. R. (Folía - muerte - reflejo). En mí erro. } \\
\text { Es, sí, eros. Fi ama a ro. ¡Para toda la vida! Efímero. } \\
\text { Efímeros } \\
\text { Aragon realiza aquí un juego de palabras basado en las } \\
\text { variaciones gráficas -y por ende, de significado- de una } \\
\text { pronunciación, en francés, prácticamente idéntica de } \\
\text { cada uno de los segmentos de este juego con respecto } \\
\text { a la palabra éphémère. Hemos tratado humildemente } \\
\text { de conservarlo en castellano, pero ha sido difícil } \\
\text { mantenerse fiel al sentido original. La traducción literal } \\
\text { sería así "Efímero. Efe. Eme. Erre. (Locura - muerte } \\
\text { - ensoñación.) Los hechos me llevan a la deriva. Los } \\
\text { fetos, madres. Fernanda ama a Roberto. ¡Para toda } \\
\text { la vida! Efímero, efímeros" [en francés: “Éphèmere, F. } \\
\text { M. R. (Folie-mort-rêverie). Les faix, mères. Fernande } \\
\text { aime Robert. Pour la vie! Éphèmere. Éphémères"]. Por } \\
\text { añadidura, el verbo errer (tanto en sentido de "errar", } \\
\text { como en el de "divagar") es, como en castellano, } \\
\text { intransitivo, pero Aragon lo convierte en transitivo para } \\
\text { dar idea de la divagación intelectual a la que lo empujan } \\
\text { los hechos, una suerte de flânerie contemplativa. }\end{array}$ \\
\hline
\end{tabular}




\begin{tabular}{|c|c|c|}
\hline Original (página) & Traducción (página) & $\begin{array}{l}\text { PALABRA ANOTADA } \\
\text { Nota de la traductora }\end{array}$ \\
\hline $\begin{array}{l}\text { II y a des mots qui sont des } \\
\text { miroirs, des lacs optiques } \\
\text { vers lesquels les mains se } \\
\text { tendent en vain. Syllabes } \\
\text { prophétiques : mon cher } \\
\text { Desnos, prenez garde aux } \\
\text { femmes dont le nom sera } \\
\text { Faënzette ou Françoise, } \\
\text { prenez garde à ces feux de } \\
\text { paille qui pourraient devenir } \\
\text { des bûchers, ces femmes } \\
\text { éphémèrement aimées, ces } \\
\text { Florences, ces Ferminas, } \\
\text { qu'un rien enflamme ET FAIT } \\
\text { MĖRES. (p. 111-112) }\end{array}$ & $\begin{array}{l}\text { Hay palabras que son } \\
\text { espejos, lagos ópticos } \\
\text { hacia los que las manos se } \\
\text { extienden en vano. Sílabas } \\
\text { proféticas: mi querido } \\
\text { Desnos, tenga usted cuidado } \\
\text { con aquellas féminas cuyo } \\
\text { nombre sea Faënzette o } \\
\text { Françoise, tenga cuidado } \\
\text { con aquellas alfamaradas, } \\
\text { pues podrían devenir } \\
\text { incendios, aquellas damas } \\
\text { efímeramente amadas, esas } \\
\text { florencias, aquellas ferminas, } \\
\text { pues un mero floreo inflama } \\
\text { primero sus pasiones y } \\
\text { después su seno. (p. 107) }\end{array}$ & $\begin{array}{l}\text { Y las convierte en madres } \\
\text { Aragon continúa en este párrafo su juego de palabras } \\
\text { en torno a la palabra éphémère: ces Florences, ces } \\
\text { Ferminas, qu'un rien enflamme ET FAIT MËRES. Estas } \\
\text { últimas palabras significan literalmente "y las convierte } \\
\text { en madres", que no hemos traducido así para tratar de } \\
\text { dar idea de las aliteraciones del párrafo original. }\end{array}$ \\
\hline $\begin{array}{l}\text { Elle fit cette chose } \\
\text { extraordinaire, de m'appeler } \\
\text { à elle : et moi je vins. } \\
\text { (p. 241) }\end{array}$ & $\begin{array}{l}\text { Hizo algo extraordinario: me } \\
\text { llamó a su lado, y yo acudí. } \\
\text { (p. 237) }\end{array}$ & $\begin{array}{l}\text { Y yo acudí } \\
\text { En el original: et moi je vins, que, además del sentido } \\
\text { literal de "acudir", significa en lenguaje vulgar "correrse". }\end{array}$ \\
\hline
\end{tabular}

En tales ejemplos, constatamos de nuevo la importancia que la traductora se otorga en las notas, como en la explicación del juego de palabras de "efímero", donde ella se incluye en la decisión y explica: "hemos tratado humildemente de conservarlo en castellano, pero ha sido difícil mantenerse fiel al sentido original". Al contrario de lo que expresaban Boer y Cirlot en la versión de 1979, en la que consideraban que la composición fonético-visual era intraducible y la trasvasaban de manera literal sin dar más explicaciones, García Cazorla hace partícipes a los lectores de las complicaciones que ha tenido que afrontar a la hora de conseguir una traducción lo más fiel posible al original. Lo mismo sucede en la segunda nota e la misma página, cuando las traductoras de 1979 trasvasan literalmente et fait mères por "y las hace madres" (p. 92), repitiendo simplemente que se trata del mismo problema e introduciendo las siglas "F.M.R." a la nota sin ningún tipo de explicación, mientras que la de 2016 explica en detalle la razón por la que ha traducido et fait mères por "es, sí, eros", dado que "y las convierte en madres" se trataría de una traducción literal y no se daría "idea de las aliteraciones del párrafo original".

\section{A modo de conclusión}

El principal objetivo de este análisis ha sido comparar las notas de El campesino de París (1979), la traducción de Noëlle Boer y Victoria Cirlot para Bruguera, con las de El aldeano de París (2016), de Vanesa García Cazorla para Errata Naturae. Pretendíamos así confirmar el cambio que se ha experimentado en España en lo que se refiere a la presencia del traductor en las novelas eruditas o dirigidas a un público minoritario, gracias especialmente a la labor desempeñada por las editoriales independientes que 
empezaron a surgir en España a partir de los años 2000. Como García Cazorla aclaró en nuestra entrevista, estas editoriales pequeñas ponen mucho cuidado en la edición de sus obras y son sumamente respetuosas con el trabajo de sus traductores, por lo que la determinación de mantener todas sus extensas notas se deba quizá a ese respeto de dichas editoriales hacia sus traductores. Añadió, además, que ninguna editorial había eliminado nunca ninguna de sus notas.

Gracias al estudio realizado, hemos comprobado que, efectivamente, hay menos notas en la traducción de 1979 que en la de 2016 - 44 notas frente a 56-, y que las de 1979 son más impersonales y teóricamente más objetivas que las de 2016. Con esto hemos podido deducir que la traductora de la última edición adquiere un protagonismo especial en el libro; da la impresión de que esta "dialoga con sus lectores cuando explica minuciosamente las decisiones que ha tomado a la hora de trasvasar ciertos términos o conceptos problemáticos. En cambio, las notas de las traductoras de $E l$ campesino de París (1979) son mucho más cortas, sin ningún tipo de explicación complementaria, lo que nos hace llegar a pensar que la editorial y las traductoras estaban casi seguras de que el público que iba a leer la obra de Aragon en 1979 era erudito - con nociones de francés y conocimientos generales históricos y culturales relacionados con Francia-, por lo que en algunas ocasiones no aclararon muchos de los términos lingüísticos o culturales desconocidos para el público general. A esto hay que sumar que, en esa época, el francés era la lengua extranjera que más se enseñaba en España.

Es posible también que las notas de la traducción de 2016 sean más largas y más detalladas que las de 1979 porque tanto Errata Naturae como su traductora saben, aunque sea de forma inconsciente, que los lectores actuales de este tipo de texto no dominan forzosamente el francés ni los conceptos históricos o culturales relacionados con Francia por estar estos más distanciados temporalmente de la obra original de 1926.

Después de comparar ambas traducciones, está claro, pues, que las editoriales han tenido en ambos casos un papel fundamental a la hora de visibilizar a las traductoras. Sin embargo, en lo que respecta a El campesino de París (1979), Boer y Cirlot emplean a menudo fórmulas impersonales cuando escriben sus anotaciones, mientras que García Cazorla, traductora de El aldeano de París (2016), utiliza sobre todo la primera persona del plural para así visibilizarse aún más y personalizar en cierto modo sus decisiones. Asimismo, el reconocimiento que Errata Naturae expresa a García Cazorla en la nota bene del libro de Aragon no hace más que corroborar el deseo de la editorial de dar a conocer la ardua labor traductológica de dicha trujamana en el momento de interpretar a uno de los autores franceses más complejos del siglo XX. 


\section{Bibliografía}

\subsection{Fuentes primarias}

- Aragon, Louis (1926). Le Paysan de Paris. París: Gallimard.

- - (1972). Le Paysan de Paris. París: Gallimard.

- - (1979). El campesino de París, Noëlle Boer y Victoria Cirlot (trads.). Barcelona: Bruguera.

- - (2016). El aldeano de París, Vanesa García Cazorla (trad.). Madrid: Errata Naturae.

\subsection{Fuentes secundarias}

- Berman, Antoine (1990). La retraduction comme espace de la traduction. Palimpsestes, 4, 1. < https://journals.openedition.org/palimpsestes/596> [Consulta: 2 junio 2019].

- Donaire Fernández, María Luisa (1991). (N. del T.): Opacidad lingüística, idiosincrasia cultural. En Traducción y adaptación cultural: España-Francia. María Luisa Donaire Fernández y Francisco Lafarga Maduell (eds.), 79-91. Oviedo: Universidad de Oviedo.

- < http://www.cervantesvirtual.com/obra/opacidad-lingstica-idiosincrasia-culturalndel-t-0/> [Consulta: 2 junio 2019].

- Gambier, Yves (1994). La retraduction, retour et détour. Meta, 39 (3), 413-417.

- Malta, Gleiton y Rael, Elaine Cunha (2015). As retraduções de La Casa de los Espíritus: uma (re)visita à hipótese da retradução. Revista Letras Raras, 4 (3), 75-97.

- Pym, Anthony (1998). Method in Translation History. Manchester: St. Jerome.

- Tahir-Gürçalar, Şehnaz (2001). Retranslation. En Routledge encyclopedia of translation studies. Mona Baker y Kirsten Malmkajaer (eds.), 125-127. Londres: Routledge.

- Toledano Buendía, Carmen (2010). ¿Qué hay tras las notas del traductor? En Lengua, traducción, recepción: en honor de Julio César Santoyo. Rosa Rabadán, Marisa Fernández López y Trinidad Guzmán González (eds.), 637-662. León: Universidad de León. <https://buleria.unileon.es/bitstream/handle/10612/4892/Toledano. pdf? sequence $=1>$ [Consulta: 2 junio 2019].

- Venuti, Lawrence (2008). The translator's invisibility. A history of translation. Londres/Nueva York: Routledge. 


\section{Notas}

1. Hay un error en la biografía, ya que La Semana Santa no se publicó en España en 1953, sino en 1970.

2. Entrevista realizada a Vanesa García Cazorla el 11 de mayo de 2020 por correo electrónico.

3. En el momento en el que Bruguera publicó la traducción de Le Paysan de Paris, había lectores especialmente interesados en Aragon y en el movimiento surrealista. Tal era el caso de la Gauche Divine ("izquierda divina", en francés), movimiento intelectual barcelonés y opuesto a la dictadura franquista, que surgió durante los años sesenta y que se componía de escritores, directores de cine o cantautores, entre otros.

4. Dicha nota bene se encuentra en una de las primeras páginas, no numeradas, de la novela.

5. Asimismo, encontramos dos notas aclaratorias que añadió Bruguera y que hemos decidido no contabilizarlas ni como culturales ni como lingüísticas. En la primera, "veinte mil francos" (p. 23), se explica que se trata de veinte mil francos "de entonces, se entiende", es decir, del valor que tenían esos francos en el año en el que se escribió la publicación. En la segunda, "los simulacros del escaparate, ya no diré nada más de aquellas figuras de cera que la moda tiene desvestidas y señaladas en la carne por el martilleo de los pulgares" (p. 45), la editorial aclara que es necesario "ver Aniceto o el panorama, novela", libro publicado por ella misma en 1978.

6. Hemos hecho uso de la colección de bolsillo Folio de la editorial Gallimard (1972).

7. No obstante, existen en Francia colecciones educativas comentadas dedicadas principalmente a alumnos de instituto y a sus profesores. Le Paysan de Paris tiene su versión anotada en las colecciones Gallimard y Folio $\left(\mathrm{n}^{\circ} 137\right.$ de La Bibliothèque Gallimard, $\mathrm{n}^{\circ} 93$ de Foliothèque, etc.). 